\title{
STRATEGI PENGEMBANGAN AGRIBISNIS KOMODITI PERTANIAN UNGGULAN DATARAN TINGGI DI KABUPATEN SUMBAWA BARAT
}

\author{
EKO SUPRIASTUTI
}

Fakultas Pertanian Universitas Cordova

Email : eko.supriastuti82@gmail.com

\begin{abstract}
ABSTRAK
Kabupaten Sumbawa Barat memiliki beberapa daerah yang ketinggiannya mencapai 586 - $800 \mathrm{~m}$ diatas permukaan laut, potensi tersebut perlu dimanfaatkan secara optimal terutama untuk memenuhi kebutuhan pangan komoditi pertanian dataran tinggi secara mandiri. Pemenuhan permintaan masyarakat terhadap komoditi pertanian dataran tinggi yang cukup besar, merupakan peluang usaha agribisnis pertanian dataran tinggi yang mempunyai prospek cerah di masa yang akan datang baik dipasar domestik bahkan berpeluang ekspor. Penelitian ini bertujuan untuk mengetahui komoditi pertanian unggulan dataran tinggi dan untuk mengetahui strategi pengembangan agribisnis komoditi pertanian unggulan dataran tinggi di Kabupaten Sumbawa Barat, dengan menggunakan metode (AHP) Analisis Hirarkhi Proses dan SWOT. Hasil penelitian dengan menggunakan AHP diketahui bahwa yang menjadi komoditi pertanian unggulan dataran tinggi dikabupaten Sumbawa Barat adalah kopi yang kedua kemiri, dengan menggunakan SWOT didapatkan prioritas strategi (1) pengembangan di tinggat petani yaitu mempertahankan dan menciptakan pasar baru dengan teknologi untuk meningkatkan harga dengan meningkatkan keaktifan kelompok tani. (2) Setrategi di tingkat pemerinntah yaitu mempertahankan bantuan pemerintah dengan motivasi kerja yang tinggi guna meningkatkan kualitas dan kuantitas olahan produksi kopi dengan jangkauan pemasaran yang luas.
\end{abstract}

Kata kunci: (AHP), Faktor internal Eksternal, SWOT.

\section{ABSTRACT}

West Sumbawa Regency has several areas whose altitude reaches 586 - $800 \mathrm{~m}$ above sea level, these potentials need to be utilized optimally, especially to meet the food needs of upland agricultural commodities independently. Fulfillment of public demand for highland agricultural commodities which is quite large, is an opportunity for upland agricultural agribusiness that has bright prospects in the future, both in the domestic market and even in export opportunities.This study aims to determine the superior agricultural commodities of the highlands and to determine the strategy of developing agribusiness for the superior agricultural commodities of the highlands in West Sumbawa Regency, using the Hierarchical Process Analysis (AHP) and SWOT methods. The results of the study using AHP revealed that the leading agricultural commodity in the highlands in West Sumbawa Regency is coffee, the second is candlenut. Using SWOT, the priority strategy is (1) development at the farmer level, namely maintaining and creating new markets with technology to increase prices by increasing activity. farmers. (2) The strategy at the government level is to maintain government assistance with high work motivation in order to improve the quality and quantity of processed coffee production with a wide marketing reach.

Keywords: (AHP), Internal External Factors, SWOT.

\section{PENDAHULUAN}

Pertanian merupakan sektor ekonomi strategis di Sumbawa Barat, walaupun nilai tambah yang dihasilkan tidak sebesar sektor pertambangan, namun penyerapan tenaga kerja pada sektor ini tertinggi dibandingkan sektor lainnya. Kabupaten Sumbawa Barat memiliki beberapa daerah yang ketinggiannya mencapai $586-800 \mathrm{~m}$ diatas permukaan laut, potensi tersebut 
perlu dimanfaatkan secara optimal terutama untuk memenuhi kebutuhan pangan komoditi pertanian dataran tinggi secara mandiri. Pemenuhan permintaan masyarakat terhadap komoditi pertanian dataran tinggi yang cukup besar, merupakan peluang usaha agribisnis pertanian dataran tinggi yang mempunyai prospek cerah di masa yang akan datang baik dipasar domestik bahkan berpeluang ekspor. Pengusahaan pertanian dataran tinggi dengan sistem agribisnis adalah solusi mengangkat citra kualitas produk pertanian dataran tinggi Sumbawa Barat agar dapat bersaing dengan produk pertanian dataran tinggi impor dan juga meningkatkan nilai ekonomi sehingga pendapatan petani meningkat.

Mengembangkan agribisnis komoditi pertanian unggulan dataran tinggi. Oleh karena itu diperlulakan suatu metode untuk menentukan prioritas komoditi pertanian unggulan dataran tinggi yaitu dengan judul penelitian "Strategi Pengembangan Agribisnis Komoditi Pertanian Unggulan Dataran Tinggi Di Kabupaten Sumbawa Barat".

\section{Perumusan Masalah}

Rumusan masalah dalam penelitian adalah :
Dataran tinggi yang ada di Kabupaten Sumbawa Barat saat ini sudah mampu memproduksi tanaman pangan, seperti kopi, buah-buahan dan sayuran masih menjadi komoditi perkebunan utama yang dikembangkan di Sumbawa Barat. Namun nilai produksi komoditi pertanian dataran tinggi tersebut masih relatif kecil, Sehingga jumlah produksi belum mampu memenuhi jumlah permintaan masyarakat di kabupaten Sumbawa Barat. Hal ini dikarena kurangnya pengetahuan masyarakat tentang penentuan komoditi pertanian unggulan dataran tinggi yang harus mereka kembangkan sesuai dengan kondisi alam setempat, serta setrategi dalam

1. Apakah yang menjadi komoditi pertanian unggulan dataran tinggi di Kabupaten Sumbawa Barat.

2. Strategi apa yang harus digunakan dalam mengembangkan agribisnis komoditi pertanian unggulan dataran tinggi di Kabupaten Sumbawa Barat.

\section{Tujuan}

Adapun tujuan dalam penelitian ini adalah

1. Untuk mengetahui komoditi pertanian unggulan dataran tinggi di Kabupaten Sumbawa Barat. 
3. Untuk mengetahui strategi pengembangan agribisnis komoditi pertanian unggulan dataran tinggi di Kabupaten Sumbawa Barat

\section{TINJAUAN PUSTAKA}

\section{Komoditi Unggulan}

Keunggulan komperatif bagi komoditi suatu Negara atau Daerah adalah komoditi itu lebih unggul secara relatif dengan komoditi lain di daerahnya. Pengertian unggul dalam hal ini adalah dalam bentuk perbandingan bukan dalam bentuk nilai tambah riil. Keunggulan komperatif adalah kegiatan ekonomi yang secara perbandingannya lebih menguntungkan bagi pengembangan daerah (Supriastuti. 2014).

\section{Usaha Agribisnis}

Agribisnis adalah suatu kesatuan kegiatan usaha yang meliputi salah satu atau keseluruhan dari mata rantai produksi, pengolahan hasil dan pemasaran yang ada hubungannya dengan pertanian dalam arti luas. Sistem, agribisnis memiliki pola keterpaduan antara subsistem agroinput, subsistem produksi tanaman (farming), subsistem pengolahan hasil panen (processing), subsistem pemasaran (marketing), dan subsistem dukungan produk pertanian (agroservices).

\section{Dataran Tinggi}

Dataran Tinggi adalah adalah dataran yang terletak pada ketinggian diatas $700 \mathrm{~m}$ dpl. Datran tinggi terbentuk sebagai hasil erosi dan sedimentasi. Dataran tinggi juga bias terbentuk karena bekas kaldera yang luas,yang tertimbun material-material dari lereng gunung yang berada di sekitarnya.

\section{Analytical Hierarchy Process (AHP)}

AHP merupakan suatu model matematika untuk mendukung dalam menentukan suatu keputusan, yang dikembangkan oleh Thomas L. Saaty. Model pendukung keputusan ini akan menguraikan masalah multi faktor atau multi kriteria yang kompleks menjadi suatu hierarchy, menurut Saaty (1993) dalam supriastuti. E. 2014, hierarchy didefinisikan sebagai suatu representasi dari sebuah permasalahan yang kompleks dalam suatu struktur multi level dimana level pertama adalah tujuan, yang diikuti level faktor, kriteria, sub kriteria, dan seterusnya ke bawah hingga level terakhir dari alternatif.

\section{Analisis SWOT}

Analisis SWOT merupakan cara untuk mengidentifikasi berbagai faktor secara sistematis dalam merumuskan rencana atau program dan strategi dengan memaksimalkan kekuatan (strength), kesempatan (oppotunity), namun secara 
bersamaan dapat meminimalkan kelemahan (weaknesses), dan ancaman (threat) yang dihadapi. Marimin, 2004.

\section{METODE PENELITIAN}

Penelitian pengembangan agribisnis komotiti unggulan dataran tinggi di Kabupaten Sumbawa Barat dilaksanakan di Kecamatan Berang Rea karena wilayah ini sangat potensial untuk pengembangan agribisnis komotiti unggulan dataran tinggi yang berlokasi di Desa Rarak. Penelitian ini dilakukan selama 3 (tiga) bulan 90 hari kerja mulai dari Bulan September sampai dengan November 2018.

\section{Jenis dan Sumber Data}

Data yang dikumpulkan pada penelitian ini terdiri atas data kuantitatif dan data kualitatif dari sumber data data primer dan skunder. Data primer merupakan data yang dikumpulkan dari nara sumber atau responden di lapangan seperti nara sumber/ahli, petani/kelompok tani, dan stakeholder pertanian baik pemerintah daerah maupun swasta.

\section{Cara Pengumpulan Data}

Teknik pengumpulan data yang digunakan pada penelitian ini yaitu sebagai berikut :
1. Studi dokumentasi (dokumentation research)..

2. Studi lapangan (field research)

\section{Analisis Data}

Penelitian ini menerapkan analisis sesuai dengan tujuan penelitian ini yaitu :

1. Kasus dalam rangka analisis dan penetapan komoditi pertanian unggulan dataran tinggi metode analisis yang digunakan adalah (AHP).

2. Dalam menentukan strategi pengembangan agribisnis komoditi pertanian unggulan dataran tinggi dilakukan dengan analisis SWOT.

\section{HASIL DAN DISKUSI}

Kabupaten Sumbawa Barat terletak dibagian barat Pulau Sumbawa, yang memiliki luas wilayah sekitar $1.849,02 \mathrm{KM}^{2}$ terletak pada posisi $116,42^{0}$

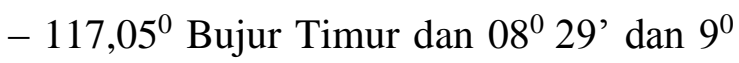
07 ' Lintang Selatan, dengan ketinggian 01.730 meter di atas permukaan laut. Wilayah dengan ketinggian ini sangat cocok untuk mengengkan komoditi pertanian dataran tinggi, terutama pada kopi.

\section{Penentuan Komoditi Pertanian Unggulan Dataran Tinggi di Kabupaten Sumbawa Barat}

Dalam menentukan komoditi pertanian unggulan dataran tinggi di Kabupaten Sumbawa Barat, peneliti mengambil 3 subsektor pertanian yaitu Tanaman Pangan, Hortikultura dan Perkebunan, dengan menggunakan dua 
aspek tujuan yaitu pertumbuhan ekonomi dan daya saing daerah dengan menggunakan analisis hierarki process, hasil analisis disajikan pada tabel 1.

Tabel 1: Skor Terbobot dan Rangking Sektor Menurut Aspek Tujuan di Kabupaten Sumbawa Barat Tahun 2018.

\begin{tabular}{lcccc}
\hline \multirow{2}{*}{ Sub Sektor } & $\begin{array}{c}\text { Pertumbuhan } \\
\text { Ekonomi }\end{array}$ & Daya Saing Daerah & $\begin{array}{c}\text { Skor } \\
\text { Terbobot }\end{array}$ & Rangking \\
\cline { 2 - 3 } & 0.562 & 0.438 & 0,358 & 2 \\
\hline Tanaman pangan & 0,363 & 0,350 & 0,471 & 1 \\
\hline Perkebunan & 0,475 & 0,467 & 0,171 & 3 \\
\hline Hortikultura & 0,162 & 0.183 & \\
\hline
\end{tabular}

Tabel 1 diatas diketahui bahwa untuk menetapkan komoditi unggulan dataran tinggi di Kabupaten Sumbawa Barat maka sektor perkebunan menduduki rangking pertama dengan skor 0,471 , dalam mencapai tujuan pertumbuhan ekonomi yaitu 0,475 , serta tujuan untuk daya saing daerah adalah sektor perkebunan dengan nilai yaitu 0,467 .

Penentuan Prioritas Komoditi Pertanian Unggulan Dataran Tinggi Lintas Sub sektor

Tabel 2: Hasil Analisis AHP Berdasarkan Urutan Rangking Komoditi Unggulan Lintas 3 Subsektor Pertanian di Kabupaten Sumbawa Barat tahun 2018.

\begin{tabular}{ccccc}
\hline $\begin{array}{c}\text { Sektor/Sub } \\
\text { sektor }\end{array}$ & $\begin{array}{c}\text { Komo } \\
\text { diti }\end{array}$ & $\begin{array}{c}\text { Skor } \\
\text { terbo } \\
\text { bot }\end{array}$ & $\begin{array}{c}\text { Uruta } \\
\text { n } \\
\text { rangk } \\
\text { ing }\end{array}$ \\
\hline 1 & Perkebunan & Kopi & 0,205 & 1 \\
& & & 4 & \\
\hline 2 & Perkebunan & Kemir & 0,157 & 2 \\
& & i & 3 & \\
\hline 3 & Tanaman & Padi & 0,133 & 3 \\
& Pangan & & 4 & \\
\hline
\end{tabular}

Hasil penelitian tentang penetuan prioritas komoditi pertanian dataran tinggi unggulan di Kabupaten Sumbawa Barat berdasarkan gabungan pendapat para pakar dengan menggunakan analisis hierarki proses diperoleh 9 (sembilan) komoditi uggulan lintas subsektor berdasarkan urutan nilai skor terbobot terlihat bahwa yang memiliki nilai rangking tertinggi adalah Sub sektor perkebunan, yaitu komoditi kopi dengan skor terbobot $(0,2054)$. komoditi tersebut di sajikan pada tabel 2.

\begin{tabular}{lllcc}
\hline 4 & $\begin{array}{l}\text { Tanaman } \\
\text { Pangan }\end{array}$ & $\begin{array}{l}\text { Jagun } \\
\text { g }\end{array}$ & $\begin{array}{c}0,122 \\
4\end{array}$ & 4 \\
\hline 5 & Tanaman & Kedel & 0,101 & 5 \\
& Pangan & ai & 8 & \\
\hline 6 & Perkebunan & Kakao & 0,108 & 6 \\
& & & 7 & \\
\hline 7 & Hortikultura & Pisang & 0,162 & 7 \\
& & 1 & \\
\hline 8 & Hortikultura & Pakis & 0,057 & 8 \\
& & & 7 & \\
\hline 9 & Hortikultura & Bawa & 0,051 & 9 \\
& & $\begin{array}{l}\text { ng } \\
\text { Putih }\end{array}$ & 3 & \\
\hline
\end{tabular}

Sumber : Data primer diolah, 2018 
Hal ini aspek tujuan menunjukkan bahwa perkebunan memang mendapatkan skor terbobot tertinggi baik dari pertumbuhan ekonomi maupun daya saing daerah. Hasil lapangan yang menunjukkan bahwa semua masyarakat yang ada di daerah Rarak mengandalkan perekonomiannya dari hasil kopi, karena hasil produksi kopi dapat meningkatkan pendapatan masyarakat setempat. Hasil kopi di Rarak juga mampu bersaing dengan kopi-kopi dari daerah lain yang ada di pulau Sumbawa. Hal ini terbukti bahwa hasil produksi kopi rarak di pasarkan sampai luar daerah Sumbawa Barat, seperti Sumbawa Besar, Lombok bahkan sampai ke pulau jawa.

Daerah Rarak baru mengembangkan jenis biji kopi robusta, namun daerah ini menjadi sentra pengembangan kopi luwak pertama dan terbesar di NTB. Potensi pada pengembangan agribisnis kopi masih mempunyai peluang yang besar, namun potensi yang ada tersebut masih belum diupayahkan dengan maksimal bila dilihat dari sumber daya manusia dan sarana lainnya (penerangan).

\section{Strategi Pengembangan Agribisnis Komoditi Unggulan Dataran Tinggi (Kopi) di Kabupaten Sumbawa Barat.}

Untuk mengetahui strategi yang digunakan dalam pengembangan agribisnis kopi, terlebih dahulu mengidentifikasi faktor-faktor yang mempengaruhi pengembangan kopi di Kabupaten Sumbawa Barat, yang terdiri dari faktor lingkungan internal dan eksternal.

\section{Analisis Lingkungan Internal kopi di Kabupaten Sumbawa Barat}

Faktor lingkungan internal yang berpengaruh terhadap pengembangan agribisnis kopi di Kabupaten Sumbawa Barat terdiri dari kekuatan dan kelemahan. Faktor kekuatan meliputi jumlah produksi, sumber daya alam, pemasaran, dan kelembagaan. Untuk lebih jelasnya dapat dilihat pada tabel 3. 
Tabel 3: Matrik Evaluasi Faktor Eksternal Kekuatan dan Kelemahan Pengembangan Agribisnis Kopi di Kabupaten Sumbawa Barat Tahun 2018

\begin{tabular}{|c|c|c|c|c|}
\hline & Uraian Faktor-Faktor Internal & Rating & Bobot & Skor \\
\hline \multicolumn{5}{|c|}{ Kekuatan (S) } \\
\hline 1 & Jumlah produksi kopi & 4.182 & 0.135 & 0.562 \\
\hline 2 & Kondisi luas lahan petani kopi & 3.909 & 0.126 & 0.491 \\
\hline 3 & Harga kopi tinggi & 4.091 & 0.132 & 0.538 \\
\hline 4 & Jumlah tenaga kerja & 3.909 & 0.126 & 0.491 \\
\hline 5 & Motivasi tenaga kerja & 3.727 & 0.120 & 0.447 \\
\hline 6 & Varietas kopi yang ditanam & 3.818 & 0.123 & 0.469 \\
\hline 7 & Jumlah dan kualitas kopi yang dipasarkan & 3.545 & 0.114 & 0.404 \\
\hline \multirow[t]{2}{*}{8} & Kelembagaan kelompok tani & 3.909 & 0.126 & 0.491 \\
\hline & TOTAL. A & 31.091 & 1.000 & 3.895 \\
\hline \multicolumn{5}{|c|}{ Kelemahan (W) } \\
\hline 1 & Sistem irigasi kopi & 3.625 & 0.139 & 0.505 \\
\hline 2 & Penggunaan modal usaha & 3.250 & 0.125 & 0.406 \\
\hline 3 & Waktu dan cara pemasaran kopi kering & 3.500 & 0.135 & 0.471 \\
\hline 4 & Keterampilan tenaga kerja & 3.125 & 0.120 & 0.376 \\
\hline 5 & Pemasaran kopi olahan (bubuk) rendah & 3.375 & 0.130 & 0.438 \\
\hline 6 & Penerapan teknik budidaya kopi masih rendah & 2.750 & 0.106 & 0.291 \\
\hline 7 & $\begin{array}{l}\text { Sarana penunjang (jalan, penerangan, dan alat } \\
\text { trasportasi) }\end{array}$ & 3.375 & 0.130 & 0.438 \\
\hline \multirow[t]{3}{*}{8} & Kurangnya kerjasama toko renakan (pemasar) & 3.000 & 0.115 & 0.346 \\
\hline & TOTAL. B & 26.00 & 1.00 & 3.272 \\
\hline & & & & 0.623 \\
\hline
\end{tabular}

Faktor yang paling dominan di Kabupaten Sumbawa Barat sebagai faktor kekuatan yaitu jumlah produksi kopi tinggi dengan skor (0.562). BPS tahun 2015 menyatakan bahwa hasil produksi kopi di Rarak sejumlah 149,5 ton dengan luas lahan 250 ha. Hal ini sesuai dengan hasil lapangan bahwa berapapun jumlah produksi yang dihasilkan petani, pembeli tetap membeli kopi dengan harga yang stabil. Harga perkilo kopi kering saat ini mencapai Rp. 28.000 - Rp. 30.000 per kilo. Selain faktor kekuatan pengembangan agribisnis kopi juga memiliki kelemahan meliputi: waktu dan cara pemasaran kopi kering, Keterampilan tenaga kerja, pemasaran kopi olahan (bubuk) rendah, penerapan teknik budidaya kopi masih rendah, sarana penunjang (jalan, penerangan, dan alat trasportasi), Kurangnya kerjasama toko 
renakan (pemasar). Dari beberapa kelemahan yang ada sarana penunjang (jalan, penerangan, dan alat trasportasi) merupakan faktor yang paling dominan lemah yaitu dengan skor (0.291).

\section{Analisis Lingkungan Eksternal Pengembangan Agribisnis Kopi di Kabupaten Sumbawa Barat}

Faktor lingkungan eksternal terdiri dari peluang dan ancaman. Secara rinci terkait peluang dan ancaman pengembangan agribisnis kopi dapat dilihat pada tabel 4 .

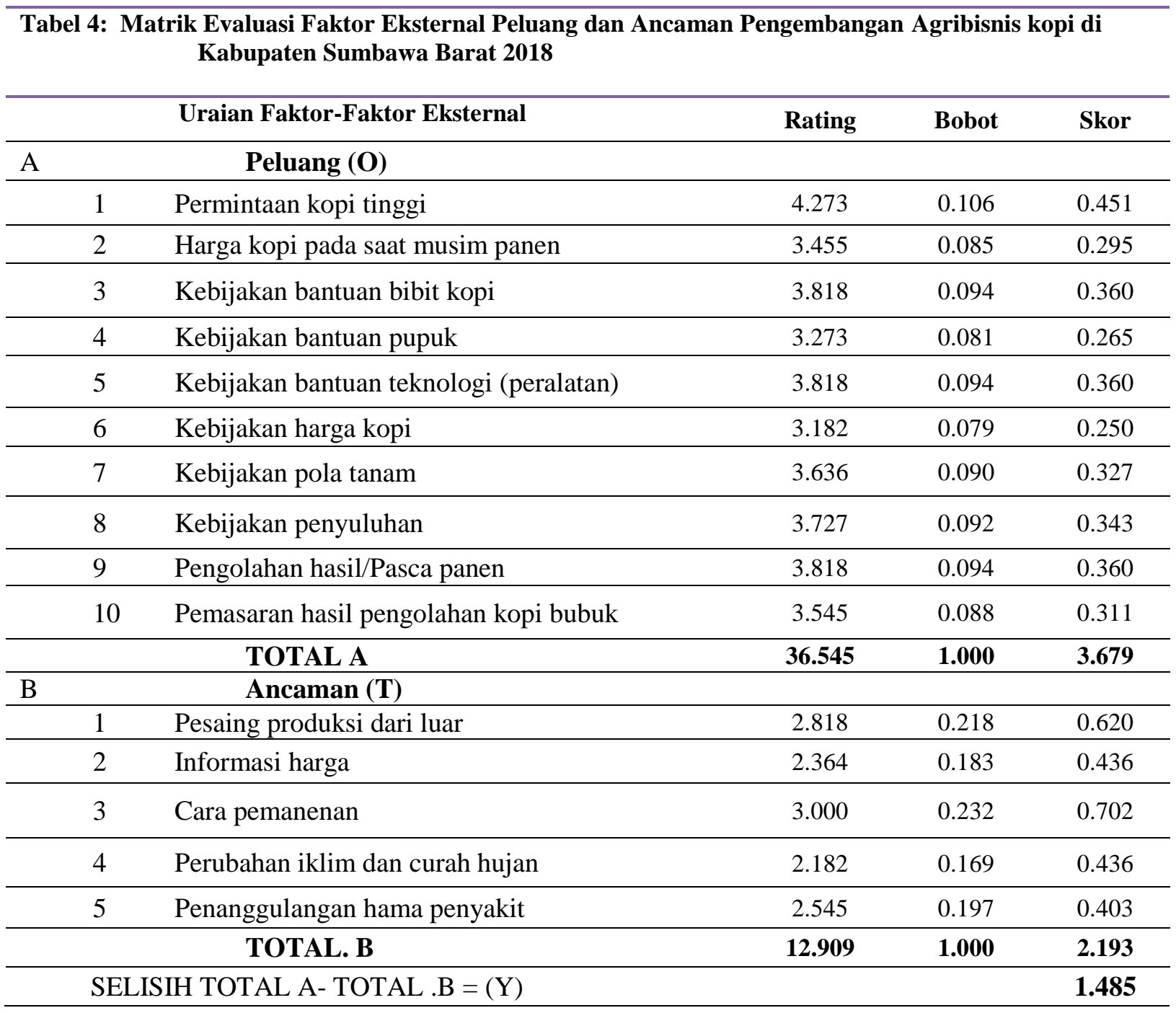

Meningkatnya konsumsi kopi dikarenakan oleh semakin bertambahnya masyarakat pencita kopi dan ditunjang oleh usaha pemerintah di bidang perkebunan adalah meningkatkan pendapatan petani Indonesia. Akan tetapi daya beli kopi masyarakat Kabupaten Sumbawa Barat tidak terlalu tinggi. Maka 
dari itu petani sebagian besar menjual hasil kopinya ke luar daerah seperti Sumbawa Besar, dan sebagian di beli oleh pengusaha yang datang ke lokasi dan dipasarkan keluar daerah. Sehingga harga kopi dari tahun 2013 sampai tahun 2018

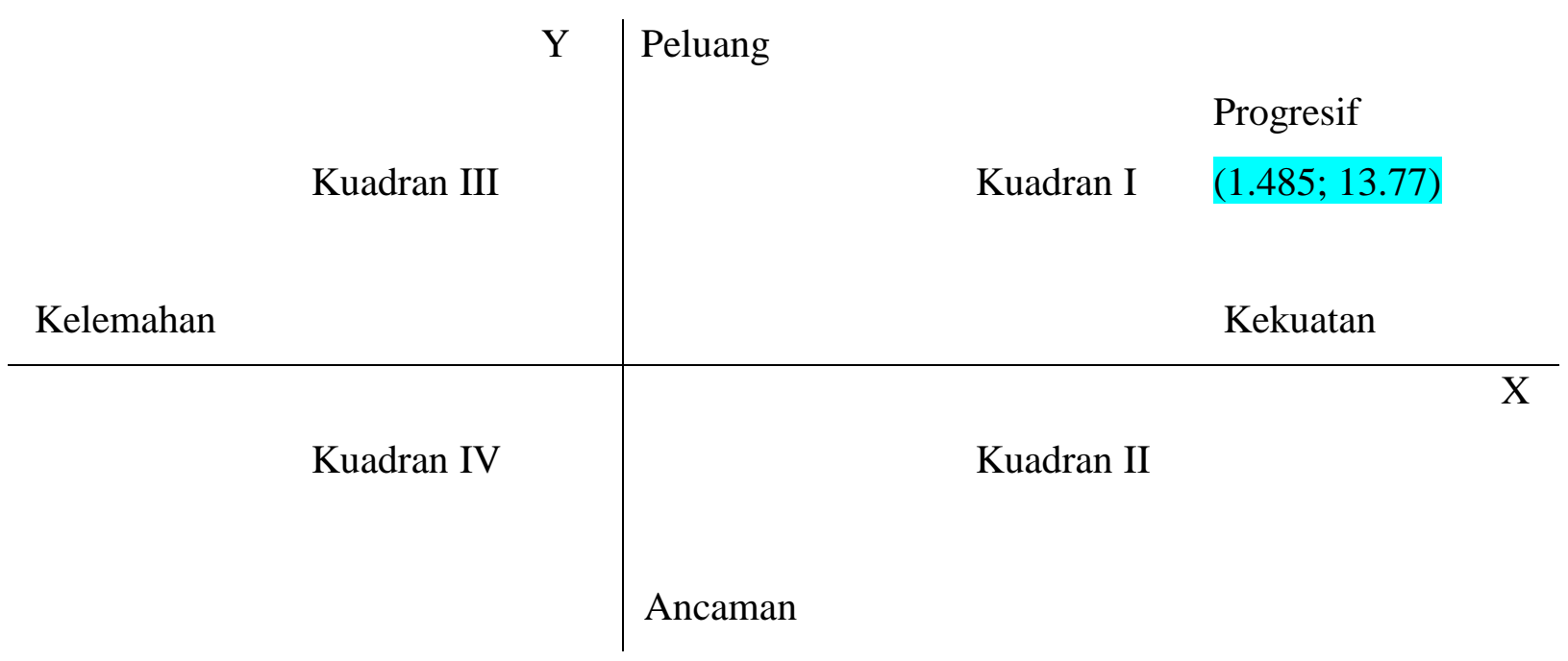

\section{Gambar 1: Posisi Kuadran}

Ancaman terbesar dalam pengembangan agribisnis kopi adalah cara penanggulangan hama penyakit yaitu dengan skor (0.403). Masyarakat Desa Rarak dalam pengembangan kopi masih secara tradisional. Pemerintah dalam hal ini tetap melakukan upayah di antaranya penagadakan pelatihan diataranya cara penanggulangan penyakit, yaitu dengan memberikan bantuan obat-obatan pada tanaman kopi. Hama yang sering menyerang kopi adalah hama bubuk yang menyerang pada buah dan hama ulat penggerek yang menyerang pada batang mengalami peningkatan yang cukup tinggi yaitu dari Rp.23.000 menjadi Rp. 28.000 per kilo gram.

Lebih jelasnya dapat dilihat pada gambar $1 . \quad$ berikut ini. 
prima dan mantap sehingga sangat memperbesar pertumbuhan dan meraih dimungkinkan untuk terus melakukan kemajuan secara maksimal pada agribisnis pengembangan agribisnis kopi, kopi.

Tabel 5. Matrik SWOT Pengembangan Agribisnis pengembangan Kopi

\begin{tabular}{|c|c|c|}
\hline EKSTERNAL & $\begin{array}{l}\quad \text { Kekuatan (S) } \\
\text { 1. Jumlah produksi kopi } \\
\text { 2. luas lahan petani kopi } \\
\text { 3. Harga kopi tinggi } \\
\text { 4. Jumlah tenaga kerja } \\
\text { 5. Motivasi tenaga kerja } \\
\text { 6. Varietas kopi yang ditanam } \\
\text { 7. Kualitas dan kuantitas kopi yang } \\
\text { dipasarkan } \\
\text { 8. Kelembagaan kelompok tani }\end{array}$ & \begin{tabular}{l}
\multicolumn{1}{c}{ Kelemahan $(\mathrm{W})$} \\
Penggunaan modal usaha \\
Sistem irigasi kopi \\
Waktu dan cara pemasaran \\
Keterampilan tenaga kerja \\
Pemasaran kopi olahan \\
Penerapan teknik budidaya kopi \\
Sarana penunjang \\
Kurangnya kerjasama
\end{tabular} \\
\hline \begin{tabular}{l}
\multicolumn{3}{c}{ Peluang $(\mathrm{O})$} \\
1. Permintaan kopi tinggi \\
2. Harga kopi saat musim \\
panen \\
3. Kebijakan bantuan bibit \\
kopi \\
4. Kebijakan bantuan pupuk \\
5. Kebijakan bantuan \\
teknologi \\
6. Kebijakan harga kopi \\
7. Kebijakan pola tanam \\
8. Kebijakan penyuluhan \\
9. Pengolahan hasil/pasca \\
panen \\
10. Pemasaran hasil \\
pengolahan kopi \\
Ancaman (T) \\
1. Menghadapi adanya \\
pesaing \\
2. Ketersediaan informasi \\
harga \\
3. Cara pemanenan \\
4. Perubahan iklim \\
5. Penanggulangan hama \\
penyakit
\end{tabular} & $\begin{array}{l}\text { 1. Meningkatkan jumlah produksi } \\
\text { dengan memaksimalkan penggunaan } \\
\text { lahan dan tenaga kerja untuk } \\
\text { memenuhi pemintaan. ( } 1,2,4 ; \mathrm{O} 1) \\
\text { 2. Meningkatkan keaktifan kelompok } \\
\text { tani agar mempermudah pemerintah } \\
\text { dalam merealisasikan kebijakannya } \\
(\mathrm{S} 3,8,6 ; \mathrm{O} 2,6,3,4,7) \\
\text { 3. Mempertahankan bantuan pemerintah } \\
\text { dengan motivasi kerja yang tinggi } \\
\text { guna meningkatkan kualitas dan } \\
\text { kuantitas olahan produksi kopi } \\
\text { dengan jangkauan pemasaran yang } \\
\text { luas. (S5,7;O5,8,9,10) }\end{array}$ & $\begin{array}{l}\text { Meningkatkan dan } \\
\text { memperbaiki sarana penunjang } \\
\text { untuk mempermudah proses } \\
\text { pemasaran serta memenuhi } \\
\text { permintaan. (W7,5;O1) } \\
\text { Meningkatkan sistem irigasi } \\
\text { dan teknik budidaya kopi } \\
\text { dengan mencanangkan program } \\
\text { unggulan terbaru( W1,2, } \\
6 ; \mathrm{O} 3,4,7,8 ; \text {; } \\
\text { Mempertahankan dan } \\
\text { menciptakan pasar baru dengan } \\
\text { teknologi untuk meningkatkan } \\
\text { harga (W3,4,8;O2,5,6,9,10) }\end{array}$ \\
\hline
\end{tabular}

Dari hasil Analisis SWOT diatas strategi yang didapat harus dilakukan secara berkesinambungan (keterkaitan) antara pemerintah dengan petani. Karena strategi ini harus berjalan serentak tentunya memerlukan biaya atau pendanaan yang tidak sedikit maka strategi kebijakan disusun berdasarkan prioritas 
untuk dapat digunakan sebagai pedoman atau dasar dalam setiap tahap pembuatan kebijakan oleh pemerintah. Maka dari itu strategi dibagi menjadi dua tingkatan yaitu (1) Strategi pengembangan pada tingkat petani dan (2) strategi kebijakan pengembangan pada tingkat pemerintah.

Strategi Kebijakan pada Tingkat Petani

Strategi yang harus di pertimbangkan oleh petani terdiri dari 5 prioritas strategi, beserta skor prioritasnya yaitu:

\section{Tabel 6: Prioritas Strategi pada Tingkat Petani untuk Mengembangkan Agribisnis kopi di Kabupaten Sumbawa Barat 2018.}

\begin{tabular}{lllcc}
\hline No & \multicolumn{1}{c}{ Prioritas Strategi } & Kode & Skor \\
\hline 1 & $\begin{array}{l}\text { Meningkatkan kualitas dan kuatitas dengan meningkatkan } \\
\text { keaktifan kelompok tani agar mendapatkan informasi harga } \\
\text { serta cara pemanenan yang tepat dalam menghadapi perubahan } \\
\text { iklim. }\end{array}$ & 3,347 \\
\hline 2 & $\begin{array}{l}\text { Memanfaatkan lahan, tenaga kerja secara maksimal dengan } \\
\text { menanam varietas unggul untuk meningkatkan jumlah produksi } \\
\text { dalam pesaingan. }\end{array}$ & ST1 & 3,214 \\
\hline 3 & $\begin{array}{l}\text { Mempertahankan dan menciptakan pasar baru dengan teknologi } \\
\text { untuk meningkatkan harga }\end{array}$ & WO3 & 2,898 \\
\hline 4 & $\begin{array}{l}\text { Meningkatkan keterampilan SDM dan menjalin kerjasama } \\
\text { dengan } \begin{array}{l}\text { rekanan untuk mendapatkan informasi guna } \\
\text { meningkatkan jumlah pemasaran dalam menghadapi pesaing. }\end{array}\end{array}$ & 2,499 \\
\hline 5 & $\begin{array}{l}\text { Meningkatkan jumlah produksi dengan memaksimalkan } \\
\text { penggunaan lahan dan tenaga kerja untuk memenuhi pemintaan. }\end{array}$ & SO1 & 2,045 \\
\hline
\end{tabular}

\section{Strategi Kebijakan pada Tingkat Pemerintah}

Strategi yang harus dipertmbangkan oleh pemerintah beserta prioritasnya dapat dilihat pada tabel berikut.

\section{Tabel 7: Prioritas Strategi pada Tingkat Pemerintah Untuk Mengembangkan Komoditi} Unggulan Dataran Tinggi Kopi di Kabupaten Sumbawa Barat.

\begin{tabular}{llllc}
\hline No & \multicolumn{1}{c}{ Prioritas Strategi } & Kode & Skor \\
\hline 1 & $\begin{array}{l}\text { Mempertahankan bantuan pemerintah dengan motivasi kerja yang } \\
\text { tinggi guna meningkatkan kualitas dan kuantitas olahan produksi } \\
\text { kopi dengan jangkauan pemasaran yang luas. }\end{array}$ & S,373 \\
\hline 2 & $\begin{array}{l}\text { Meningkatkan keaktifan kelompok tani agar mempermudah } \\
\text { pemerintah dalam merealisasikan kebijakannya }\end{array}$ & SO2 & 3,156 \\
\hline 3 & $\begin{array}{l}\text { Meningkatkan dan memperbaiki sarana penunjang untuk } \\
\text { mempermudah proses pemasaran serta memenuhi permintaan. }\end{array}$ & WO1 & 1,269 \\
\hline 4 & $\begin{array}{l}\text { Meningkatkan sistem irigasi dan teknik budidaya kopi dengan } \\
\text { mencanangkan program unggulan terbaru. }\end{array}$ & WO2 & 1,269 \\
\hline 5 & $\begin{array}{l}\text { Meningkatkan sarana penunjang dalam mengatasi penyakit untuk } \\
\text { menekan kegagalan produksi }\end{array}$ & WT1 & 3,834 \\
\hline
\end{tabular}




\section{KESIMPULAN}

Dari hasil penelitian yang peneliti lakukan, maka dapat diambil kesimpulan sebagai berikut:

1. Komoditi pertanian unggulan dataran tinggi lintas sub-sektor yang menjadi prioritas utama untuk dikembangkan di Kabupaten Sumbawa Barat adalah pengembangan kopi.

2. Strategi prioritas pengembangan agribisnis komoditi unggulan dataran tinggi kopi di Kabupaten Sumbawa Barat dibagi menjadi dua yaitu:

a. Strategi pada tingkat petani kopi yaitu mempertahankan dan menciptakan pasar baru dengan teknologi untuk meningkatkan harga dengan meningkatkan keaktifan kelompok tani

b. Setrategi di tingkat pemerinntah yaitu mempertahankan bantuan pemerintah dengan motivasi kerja yang tinggi guna meningkatkan kualitas dan kuantitas olahan produksi kopi dengan jangkauan pemasaran yang luas.

\section{DAFTAR PUSTAKA}

BPS, 2015. Sumbawa Barat Dalam Angka

BPS, 2017. Sumbawa Barat Dalam Angka

Fatma, D. 2018. Pengertian dataran tinggi. Ilmu Geografi.com

Mulyono, J. dan Munibah,K. 2016. Strategi Pembangunan Pertanian Di Kabupaten Bantul Dengan Pendekatan A'wot.

Prayitno, A. 2012. Analisis Strategi Pengembangan Agribisnis Komoditas Sayuran Unggulan Di Asosiasi Aspakusa Makmur Kabupaten Boyolali. Jurnal Mediagro. Vol. 8 No.2 : 8-20

Supriastuti, E. 2014. Aplikasi Analytical Hierarchy Process (AHP) pada penentuan komoditi pertanian unggulan di Kabupaten Sumbawa Barat. Universitas Mataram.

Rangkuti, F, 2009. Analisis Swot; Teknik Membedah Kasus Bisnis. PT. Gramedia Pustaka Utama, Jakarta.

Sukmawani, R., M. Haeruman, L. Sulistyowati, dan T. Perdana. 2014. Papaya development model as a competitive local superior commodity. Jurnal Ekonomi Pembangunan. Vol. 15(2): 128-140. 